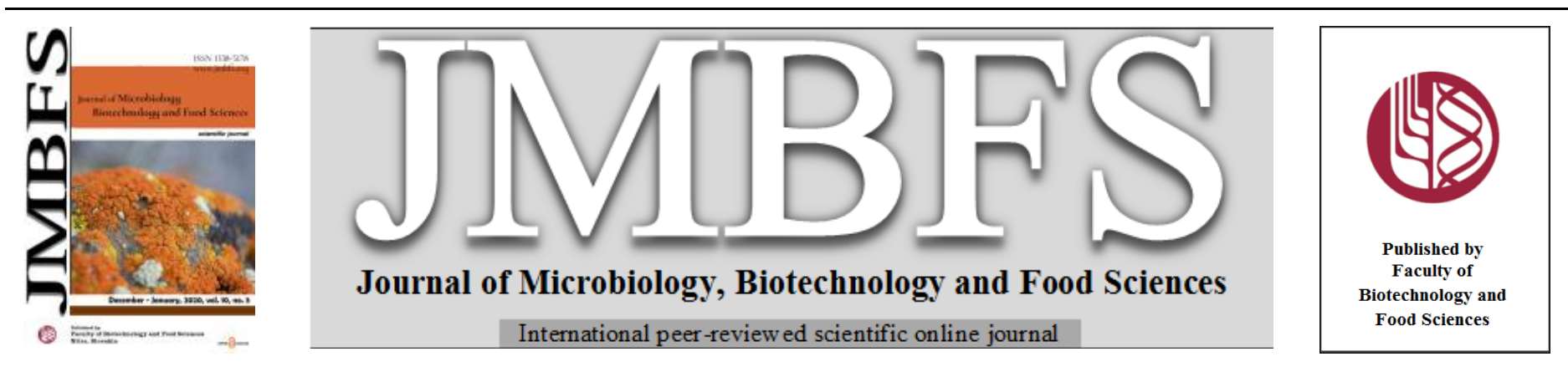

\title{
HYPOCHOLESTEROLEMIC EFFECT OF MICROWAVE ASSISTED DEFATTED FLAXSEED EXTRACT IN EXPERIMENTAL RATS
}

\author{
Anees Ahmed Khalil ${ }^{1}$, Ayesha Aslam ${ }^{* 1}$, Ahood Khalid ${ }^{1}$, QuratulAin Shahid ${ }^{1,}$ Maryam Aslam ${ }^{1}$, Miroslava Hlebová ${ }^{2}$ \\ Maksim Rebezov ${ }^{3,4,5}$,Marina Derkho ${ }^{6}$, Mohammad Ali Shariati ${ }^{7,8}$
}

\author{
$\operatorname{Address(es):~}$ \\ ${ }^{1}$ University of Lahore, Faculty of Allied Health Sciences, University Institute of Diet and Nutritional Sciences, 1-km Defense road, near Bhuptian chowk, Lahore, \\ Punjab, Phone no. (042)111-865-865. \\ ${ }^{2}$ University of SS. Cyril and Methodius, Department of Biology, Faculty of Natural Sciences, Nám. J. Herdu 2, SK-91701 Trnava, Slovak Republic. \\ ${ }^{3}$ V. M. Gorbatov Federal Research Center for Food Systems of Russian Academy of Sciences, Moscow, Russian Federation. \\ ${ }^{4}$ Prokhorov General Physics Institute, Russian Academy of Sciences, Moscow, Russian Federation. \\ ${ }^{5}$ Russian state agrarian correspondence university, Balashikha, Russian Federation. \\ ${ }^{6}$ South-Ural State Agrarian University, Troitsk, Russian Federation. \\ ${ }^{7}$ K.G. Razumovsky Moscow State University of Technologies and Management (the First Cossack University), Moscow, Russian Federation. \\ ${ }^{8}$ Food Engineering Department, Shakarim State University of Semey, Kazakhstan.
}

*Corresponding author: ayeshaaslam2016@gmail.com; m.ali.sh@semgu.kz

doi: 10.15414/jmbfs.2020.10.3.493-499

\section{ARTICLE INFO}

Received 2. 6. 2020

Revised 13. 8. 2020

Accepted 27. 8. 2020

Published 1. 12. 2020

Regular article

open $\partial$ ACCESS

\begin{abstract}
The research was aimed to determine the hypocholesterolemic property of microwave assisted defatted flaxseed extract (MADFEs) on rat model under study. The study trial included 25 male rats which were separated into 5 groups having 5 rats in each group. Twenty rats out of 25 were hypercholesterolemic and remaining 5 were normal rats. High cholesterol diet was administered for 15 days in order to induce hypercholesterolemia, and after the induction these rats were administered different concentrations of MADFEs (150, 300 \& $450 \mathrm{mg} / \mathrm{kg} \mathrm{B}$.W.) for a time interval of 28 days. A significant reduction was observed in the levels of lipid profile parameters by the administration of extracts. The extract at a dose of $300 \mathrm{mg} / \mathrm{kg} \mathrm{B.W}$. was shown to have provided optimal results displaying lowered cholesterol content, triglyceride and LDL-c by $16.79 \%, 15.41 \%$ and $12.68 \%$, while the level of HDL elevated by $14.71 \%$ in comparison to the control $\mathrm{F}_{\mathrm{o}}$ group. Likewise, the percent increase in the concentrations of catalase and SOD by $10.89 \%$ and $29.38 \%$. The study determined that MADFEs displayed hypocholesterolemic effect and can be utilized for its therapeutic benefits. The lignin present in defatted flaxseed provide with the potential against diseases.
\end{abstract}

\section{INTRODUCTION}

Hyperlipidemia is termed as elevated serum total cholesterol, triglycerides, LDL and VLDL levels, along with decrease in HDL levels that is considered to be good cholesterol (Rahaman et al., 2013). It is hazardous for cardiovascular diseases, consisting of stroke and coronary heart disease. CVD is the cause of mortality around the globe that accounts around 30\% of deaths per year worldwide (Naik et al., 2018). Flaxseeds as a whole are the source of lignins, soluble and insoluble dietary fibers, omega -3-fatty acids. Main lignin found in flaxseed, mostly present in defatted flaxseed is secoisolaricerisinol diglucodise (SDG). It is known to have great antioxidant, anti- inflammatory, angiogenic and anti -apoptotic properties. Among valuable benefits of defatted flaxseed extract, its oil is an optimum source of fatty acids (omega -3) /polyunsaturated fatty acids. Defatted flaxseed cake is obtained after oil extraction and used as a flaxseed meal by grinding it (Aslam et al., 2019). Natural products are getting fame in terms of less toxicity worldwide, and defatted flaxseed is a valuable by-product after oil extraction that can be used to treat diseases instead of wasting it.

The flaxseed fiber reduces the levels of blood cholesterol by halting and decreasing their absorption from intestine (Zanwar et al., 2013). Recently, there is a huge interest in nutraceuticals and functional food, and many studies have been shown that etiology of many degenerative diseases along with hepatopathies and organ damage is due to reactive oxygen species (ROS) and oxygen free radicals (Rajesha et al.,2006). Ferulic acid, gallic acid, caffeic acid, vanillic acid, p-coumaric acid, sinapic acid and syringic acid are the phenolics found in the flaxseed. Lignans possess a number of biological activities i.e. antitumor activity, cardiovascular, neuro- protection, immunity, antiviral and neurotropic actions (Aslam et al., 2019). Flaxseed lignans that are not steroid phytoestrogens had structural similarity to that of leaf estrogens, which suggests that mammals exhibit estrogenic effects. Intestinal bacteria metabolize flax tissue for bioavailability in plasma (Mali et al., 2019).

The SDG content varies between 9 and $30 \mathrm{mg}$ g- 1 of defatted flaxseed meal Phenolic acids and its derivatives in flax varied between 8-10 mg g- 1 of seeds (Waszkowiak et al., 2015). Flax lignans act as Phytoestrogens and antioxidants both. Linseed contains about 800 times greater lignans than other plant foods. The SDG present in foods and flaxseeds converted into enterodiol and enterolactone by gut bacteria that provide weak estrogenic or anti-estrogenic effects along with antioxidant effects. Consumption of flaxseed signifies its multiple benefits to health including reduced tumor growth, lowering serum cholesterol concentrations and lowered incidence of breast, prostrate, and colon cancers (Russo and Reggiani, 2015). Flaxseed cake is most concerned source of lignin as compared to whole flaxseed (The et al., 2015). Extraction of SDG by conventional methods results in less extraction yield and it is time consuming. Therefore, nowadays, latest techniques are being used owing their efficient yield and rapid nature. Microwave assisted extraction MAE is used by many scientists for extraction of defatted flaxseed and its phenolics. MAE has recently been used for the extraction of various bioactive molecules from tea, citrus and grapes (Abdi et al., 2017). In view of all the concerned health benefits, present study is conducted to analyze the lipid lowering effects of defatted flaxseed extract by microwave assisted technology and antioxidant indices in experimental rats. 


\section{MATERIAL AND METHODS}

\section{Chemicals and reagents}

All the chemicals and reagents used in the study were purchased from SigmaAldrich Corporation (USA). All of the chemicals used in the study were of analytical grade.

\section{Plant material collection and authentication}

Flaxseeds were purchased from local market of Lahore Pakistan. Flaxseeds were milled to reduce their particle size. Ground flaxseeds $(50 \mathrm{~g})$ were defatted by following the procedure described by AOAC (Horwitz, 2006) through Soxhlet apparatus (45-55oC) using n-hexane (200-250 mL) as a solvent for 5-7 h. For the removal of residual solvents from defatted flaxseeds they were placed in hot air oven $(40 \mathrm{oC})$. Oil and defatted flaxseeds were stored separately at $4{ }^{\circ} \mathrm{C}$ till further analysis.

\section{MAE extraction procedure}

Defatted flaxseeds of each mentioned variety was subjected to microwave assisted extraction using a Haier microwave system (Haier Corporation, Qingdao, China) operating at variable power i.e. 50 to $300 \mathrm{~W}$. Defatted flaxseed (1 g) of each variety was placed in a quart tube and added up with $25 \mathrm{~mL}$ of methanol $(70 \%)$ and $1 \mathrm{M} \mathrm{NaOH}$. MAE for each sample was carried out at $150 \mathrm{~W}$ (power) for 5 minutes (time). Afterwards, extracts were treated with acetic acid for neutralization purpose and centrifuged for collection of supernatant. Before antioxidant characterization and quantification of major phenolics in MAE defatted flaxseed extracts of each variety, the supernatant was filtered $(0.45 \mu \mathrm{m})$.

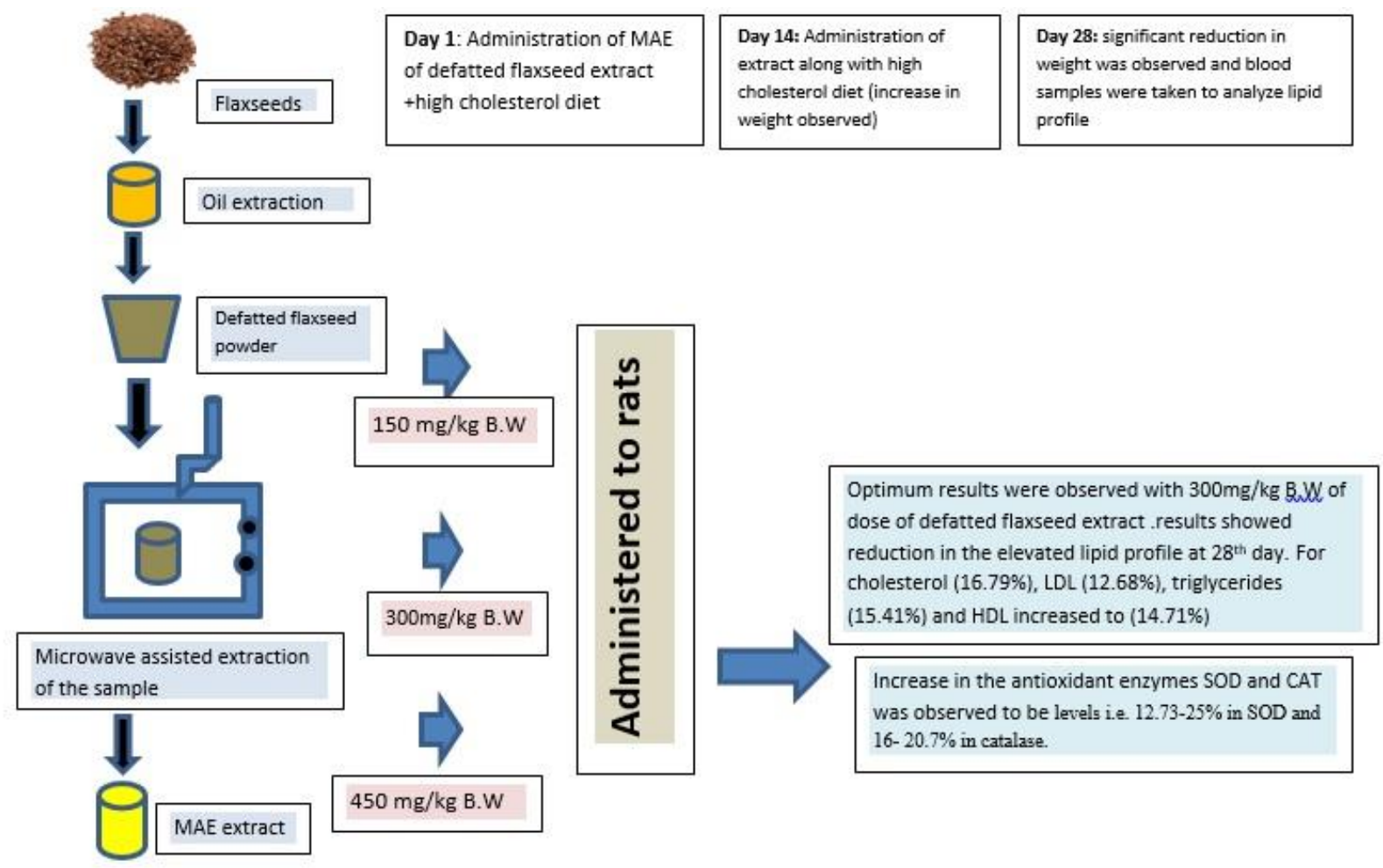

Figure 1 Graphical representation of experimental design. Microwave assisted extraction of defatted flaxseeds and administration of extracts in different doses to the study rats. After the administration analysis of the blood samples were taken to determine the lipid lowering effect of MAE of defatted flaxseed.

\section{Experimental animals}

For rat bioassay, 25 male albino rats were housed in animal room of IMBB, The University of Lahore. The rats were acclimatized by feeding on basal diet for a period of one week. The environmental conditions were controlled through the trial like temperature $\left(23 \pm 2{ }^{\circ} \mathrm{C}\right)$ and relative humidity $(55 \pm 5 \%)$ along with 12 $\mathrm{h}$ light-dark period. The experimental protocol was based on the institutional guidelines for the care and use of laboratory animals, University institute of molecular biology and biotechnology (IMBB), the University of Lahore, Lahore Pakistan. The study was approved by ethical committee of the department. Experiments on animals were performed in the animal house of IMBB, The University of Lahore.

\section{Sample size}

25 male albino rats (05 in normal group; 05 in hypercholesterolemic control group and 15 in hypercholesterolemic experimental groups were used in the experiment for rat bioassay, Rats were housed in the Institute of Molecular Biology and Biotechnology (IMBB) animal room to assess the effect of defatted flax seed extract

\section{Sampling technique}

Rats was anesthetized by isoflurane and samples were collected by cardiac puncture at following intervals; 0 day (to establish baseline trend), 15th day (to authenticate the induction of hypercholesterolemia) and then on 21 st day post administration of extract (to validate the effect of mentioned treatments).

\section{Grouping and experimental treatment plan}

Study was divided into 5 groups i.e. N0, F0, F1, F2, and F3. Group N0 was subjected to normal basal diet throughout the study, while group F0 was subjected to hypercholesterolemic diet without the administration of any extract. On the other hand, remaining groups i.e. F1, F2 and F3 was feed on hypercholesterolemic diet along with various concentrations $(150 \mathrm{mg} / \mathrm{kg} \mathrm{B}$. W, $300 \mathrm{mg} / \mathrm{kg} \mathrm{B}$. W and $450 \mathrm{mg} / \mathrm{kg} \mathrm{B}$. W) of extracts. Group F0, F1, F2, \& F3 was subjected to high cholesterol diet for first 15 days for induction of hypercholesterolemia. All the respective extracts were administrated to each rat by oral gavage along with high cholesterol diet. In this rat bioassay trial 25 rats were divided into 5 groups, each comprising of 5 rats in them.

\section{Induction of Hypercholesterolemia}

For induction of high cholesterol levels in rats, hypercholesterolemic diet was prepared and administered by using corn oil (10\%), corn starch (64.5\%), cholesterol $(1.5 \%)$, protein $(10 \%)$, mineral $(3 \%)$, cellulose $(10 \%)$ mineral and vitamin $(1 \%)$.

\section{Blood Sampling}

The effect was authenticated by examining their total cholesterol content at interval of time 0 day, 15 th day and $28^{\text {th }}$ day. Rats were anesthetized by exposure to isoflurane and the blood samples were collected through cardiac puncture for biochemical analysis. 


\section{Biochemical Analysis}

\section{Serum lipid profile}

The effect of selected defatted flaxseed extract on the serum total cholesterol, low density lipoproteins (LDL), high density lipoproteins (HDL) and triglycerides levels of rats were determined by using method as described by (El-Newary et al.,2018).

\section{Antioxidant status}

The effect of defatted flax seed extract on the glutathione contents of rats was determined by following the protocol of Butler described by Sultan et al Furthermore; the antioxidant enzyme assays include the estimation of concentration of superoxide dismutase (SOD) and catalase. The measurement of SOD activity is based on the method described by Sultan et al (Sultan et al. 2015).

\section{Statistical analysis}

Data was analyzed statistically using Statistix (9.0) software. Results were expressed as mean \pm S.D. ANOVA (analysis of variance) for completely randomized design (CRD) was performed and to assess the significance ( $\mathrm{P} \leq$ $0.05)$ differences among means Tukey's test was applied.

\section{RESULTS}

\section{Total cholesterol (TC)}

The statistical analysis reported a significant $(p \leq 0.05)$ effect of time interval $(0$, 14, 28 days) and treatment on the cholesterol levels of hypercholesterolemic experimental rats. The results of the effect of MADFEs in different concentrations $(150,300 \& 450 \mathrm{mg} / \mathrm{kg}$ B.W.) on the levels of cholesterol are presented in figure 2 . The results for levels of total cholesterol displayed peak $(16.79 \%)$ percent reduction in experimental group $\mathrm{F}_{2}$, followed by $\mathrm{F}_{1}(13.3 \%)$ and $\mathrm{F}_{3}(11.83 \%)$. In comparison to the control $\mathrm{F}_{\mathrm{o}} 194.28 \pm 1.23 \mathrm{mg} / \mathrm{dl}$ concentration of cholesterol in groups $F_{1}, F_{2}$ and $F_{3}$ were observed to be $153.52+2.55 \mathrm{mg} / \mathrm{dl}, 141.62+2.33 \mathrm{mg} / \mathrm{dl}, 158.22+1.25 \mathrm{mg} / \mathrm{dl}$ respectively, on $28^{\text {th }}$ day of administration. The highest reduction was observed in $\mathrm{F}_{2}$ group.

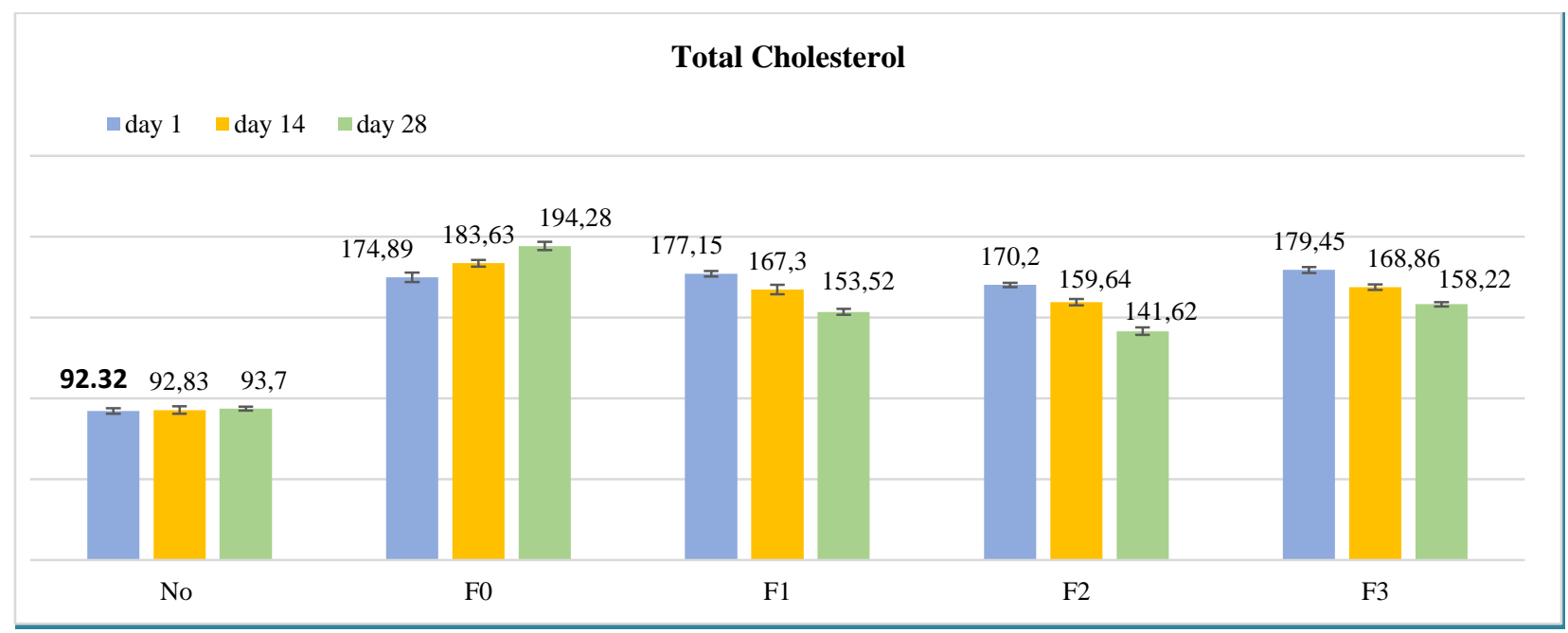

Figure 2 Analysis of cholesterol (mg/dl) in experimental rats *N0 normal group (no extract and high cholesterol diet), F0= hypercholesterolemic control group (high cholesterol diet), Treatment groups F1, F2, and F3 (high cholesterol diet +extract; $150 \mathrm{mg} / \mathrm{kg}$ b.w, $300 \mathrm{mg} / \mathrm{kg}$ b.w and 450 $\mathrm{mg} / \mathrm{kg}$ b.w respectively)

\section{Low density lipoproteins (LDL)}

The results of the statistical analysis displayed significant $(p \leq 0.05)$ effect of treatments $(150,300 \& 450 \mathrm{mg} / \mathrm{kg} \mathrm{B.W.})$ and time intervals $(0,14,28$ days $)$ on the levels of LDL in experimental rats. The results regarding the effect of MADFEs on the LDL content is presented in table 1. The LDL content was reduced from $106.77 \pm 2.04 \mathrm{mg} / \mathrm{dl}$ at 0 day to $104.80 \pm 1.63 \mathrm{mg} / \mathrm{dL}$ at $14^{\text {th }}$ day and $99.98 \pm 2.26 \mathrm{mg} / \mathrm{dl}$ at $28^{\text {th }}$ day of administration, respectively. Moreover, the LDL concentration observed in $\mathrm{F}_{\mathrm{o}}(110.77 \pm 2.36 \mathrm{mg} / \mathrm{dl})$ was decreased to $104.16 \pm 1.81$ $\mathrm{mg} / \mathrm{dl}\left(\mathrm{F}_{1}\right), 96.80 \pm 1.99 \mathrm{mg} / \mathrm{dl}\left(\mathrm{F}_{2}\right)$, and $103.67 \pm 1.78 \mathrm{mg} / \mathrm{dl}\left(\mathrm{F}_{3}\right)$, respectively. The percent reduction in comparison to hypercholesterolemic control $\mathrm{F}_{\mathrm{o}}$ was $12.68 \%$, $11.2 \%$ and $11.8 \%$; portraying highest reduction in $\mathrm{F}_{2}$.

\begin{tabular}{llllll}
\multicolumn{6}{l}{ Table 1 Analysis of low-density lipoproteins (LDL) in experimental rats } \\
\hline Parameter & Treatments & Interval of days & & \\
\hline & & 0 day & $15^{\text {th }}$ day & $28^{\text {th }}$ day & Means \\
LDL & N0 & $37.23 \pm 1.87$ & $38.67 \pm 1.21$ & $38.60 \pm 1.87$ & $38.16 \pm 1.65$ \\
$(\mathrm{mg} / \mathrm{dl})$ & F0 & $105.43 \pm 2.34$ & $110.25 \pm 1.76$ & $116.64 \pm 2.98$ & $110.77 \pm 2.36^{\text {a }}$ \\
& F1 & $110.14 \pm 1.65$ & $104.63 \pm 1.44$ & $97.72 \pm 2.31$ & $104.16 \pm 1.81^{\text {b }}$ \\
& F2 & $103.30 \pm 1.55$ & $96.89 \pm 2.12$ & $90.20 \pm 2.31$ & $96.80 \pm 1.99^{\text {c }}$ \\
& F3 & $108.19 \pm 2.65$ & $107.45 \pm 1.23$ & $95.38 \pm 1.46$ & $103.67 \pm 1.78^{\text {b }}$ \\
& & $106.77 \pm 2.04^{\text {a }}$ & $104.80 \pm 1.63^{\text {a }}$ & $99.98 \pm 2.26^{\text {b }}$ & \\
\hline
\end{tabular}

*N0 normal group (no extract and high cholesterol diet), $\mathbf{F 0}=$ hypercholesterolemic control group (high cholesterol diet), Treatment groups F1, F2, and F3 (high cholesterol diet +extract; $150 \mathrm{mg} / \mathrm{kg} \mathrm{b.w,} 300 \mathrm{mg} / \mathrm{kg}$ b.w and $450 \mathrm{mg} / \mathrm{kg}$ b.w respectively)

\section{High density lipoproteins (HDL)}

The statistical analysis demonstrated significant $(p \leq 0.05)$ effect on the HDL level in the experimental rats. The effect of MADFEs on HDL content in experimental rats are presented in table 2 . In comparison to the results of hypercholesterolemic control $F_{o}(75.420 \pm 21.83 \mathrm{mg} / \mathrm{dl})$, an elevation identified in the values of $F_{1}$
$(79.630 \pm 2.16 \mathrm{mg} / \mathrm{dl}), \quad F_{2}(83.680 \pm 2.25 \mathrm{mg} / \mathrm{dl})$ and $F_{3}(78.497 \pm 1.60 \mathrm{mg} / \mathrm{dl})$ respectively. However, the HDL levels were increased from $74.600 \pm 1.8 \mathrm{mg} / \mathrm{dl}(0$ day) to $79.075 \pm 2.3 \mathrm{mg} / \mathrm{dL}\left(14^{\text {th }}\right.$ day) and $84.245 \pm 1.8 \mathrm{mg} / \mathrm{dl}\left(28^{\text {th }}\right.$ day) respectively. The percent elevation displayed as compared to $\mathrm{F}_{\mathrm{o}}$ were $12.09 \%$, $14.71 \%$ and $11.21 \%$; highest for $\mathrm{F}_{2}$ 
Table 2 Analysis of high density lipoproteins (HDL) in experimental rats

\begin{tabular}{|c|c|c|c|c|c|}
\hline parameter & Treatments & Interval of day & & & \\
\hline \multirow{7}{*}{$\begin{array}{l}\text { HDL } \\
(\mathrm{mg} / \mathrm{dl})\end{array}$} & & 0 day & $15^{\text {th }}$ day & $28^{\text {th }}$ day & Means \\
\hline & No & $40.01 \pm 1.23$ & $42.70 \pm 1.08$ & $45.01 \pm 2.34$ & $42.57 \pm 1.55$ \\
\hline & F0 & $70.59 \pm 2.31$ & $75.51 \pm 1.67$ & $80.16 \pm 1.52$ & $75.420 \pm 1.83^{\mathrm{c}}$ \\
\hline & $\mathrm{F} 1$ & $75.34 \pm 2.18$ & $79.10 \pm 2.78$ & $84.45 \pm 1.54$ & $79.630 \pm 2.16^{b}$ \\
\hline & $\mathrm{F} 2$ & $78.21 \pm 1.98$ & $83.05 \pm 2.89$ & $89.78 \pm 1.90$ & $83.680 \pm 2.25^{\mathrm{a}}$ \\
\hline & $\mathrm{F} 3$ & $74.26 \pm 1.09$ & $78.64 \pm 1.87$ & $82.59 \pm 2.30$ & $78.497 \pm 1.75^{b}$ \\
\hline & Means & $74.600 \pm 1.8^{\mathrm{c}}$ & $79.075 \pm 2.3^{\mathrm{c}}$ & $84.245 \pm 1.8^{\mathrm{a}}$ & \\
\hline
\end{tabular}

*N0 normal group, F0 hypercholesterolemic control group (high cholesterol diet), F1, F2 and F3 (extract \&high cholesterol diet)

\section{Triglycerides (TG)}

The statistical analysis reported that time intervals and treatment have significant $(p \leq 0.05)$ effect on the levels of total triglycerides in hypercholesterolemic rats. The mean values of the TG triglycerides are mentioned in the table 3. Total triglyceride levels presented in $\mathrm{F}_{\mathrm{o}}(190.23 \pm 2.20 \mathrm{mg} / \mathrm{dl})$ decreased to $175.71 \pm 2.23$ $\mathrm{mg} / \mathrm{dl}\left(\mathrm{F}_{1}\right), 164.87 \pm 1.91 \mathrm{mg} / \mathrm{dl}\left(\mathrm{F}_{2}\right)$ and $173.52 \pm 1.82 \mathrm{mg} / \mathrm{dl}\left(\mathrm{F}_{3}\right)$, respectively.
Furthermore, triglyceride levels reduced from $181.41 \pm 1.97 \mathrm{mg} / \mathrm{dl}$ at 0 day to $177.47 \pm 1.97 \mathrm{mg} / \mathrm{dL}$ at $14^{\text {th }}$ day and $169.36 \pm 2.21 \mathrm{mg} / \mathrm{dl}$ at $28^{\text {th }}$ day, respectively. In comparison to hypercholesterolemic control $\left(\mathrm{F}_{\mathrm{o}}\right)$ considerable percent decrease of $12.25 \%, 15.41 \%, 9.89 \%$ was displayed in experimental rats. Maximum reduction was observed in group $\mathrm{F}_{2}$.

Table 3 Analysis of triglyceride (TG) in experimental rats

\begin{tabular}{|c|c|c|c|c|c|}
\hline Parameter & Treatments & Interval of days & & & \\
\hline \multirow{7}{*}{$\begin{array}{l}\text { Triglyceride } \\
(\mathrm{mg} / \mathrm{dl})\end{array}$} & & 0 day & $15^{\text {th }}$ day & $28^{\text {th }}$ day & Means \\
\hline & NO & $76.74 \pm 1.26$ & $80.37 \pm 1.23$ & $84.47 \pm 1.54$ & $80.52 \pm 1.34$ \\
\hline & F0 & $180.58 \pm 2.21$ & $189.60 \pm 1.43$ & $200.50 \pm 2.98$ & $190.23 \pm 2.20^{\mathrm{a}}$ \\
\hline & $\mathrm{F} 1$ & $185.22 \pm 1.29$ & $179.37 \pm 2.65$ & $162.53 \pm 2.76$ & $175.71 \pm 2.23^{b}$ \\
\hline & $\mathrm{F} 2$ & $178.01 \pm 2.34$ & $166.03 \pm 1.55$ & $150.57 \pm 1.98$ & $164.87 \pm 1.91^{\mathrm{c}}$ \\
\hline & F3 & $181.84 \pm 2.07$ & $174.87 \pm 2.27$ & $163.85 \pm 1.24$ & $173.52 \pm 1.82^{b}$ \\
\hline & Means & $181.41 \pm 1.97^{\mathrm{a}}$ & $177.47 \pm 1.97^{\mathrm{b}}$ & $169.36 \pm 2.21^{\mathrm{c}}$ & \\
\hline
\end{tabular}

*N0 normal group with no extract and high cholesterol diet, F0= hypercholesterolemic control group (high cholesterol diet), Treatment groups F1, F2, and F3 (high cholesterol diet +extract)

\section{Superoxide dismutase (SOD)}

Statistical analysis revealed a significant $(p<0.05)$ effect of time interval and treatment on SOD enzyme levels in experimental rats. The results of SOD levels in rats are displayed in figure 3 . The levels of SOD enzyme elevated from
$28.31 \pm 0.82 \mathrm{IU} / \mathrm{L} \quad\left(\mathrm{F}_{\mathrm{o}}\right)$ to $32.36 \pm 0.66 \mathrm{IU} / \mathrm{L} \quad\left(\mathrm{F}_{1}\right), \quad 40.09 \pm 0.99 \mathrm{IU} / \mathrm{L} \quad\left(\mathrm{F}_{2}\right)$ and $33.51+0.51 \mathrm{IU} / \mathrm{L}\left(\mathrm{F}_{3}\right)$ on $28^{\text {th }}$ day of administration of MADFEs., respectively. Furthermore, the maximum percent increase was displayed in group $\mathrm{F}_{2}(29.38 \%)$, followed by $\mathrm{F}_{3}(15.5 \%)$ and $\mathrm{F}_{1}(12.51 \%)$. The peak elevation in the levels of SOD was noted for the group

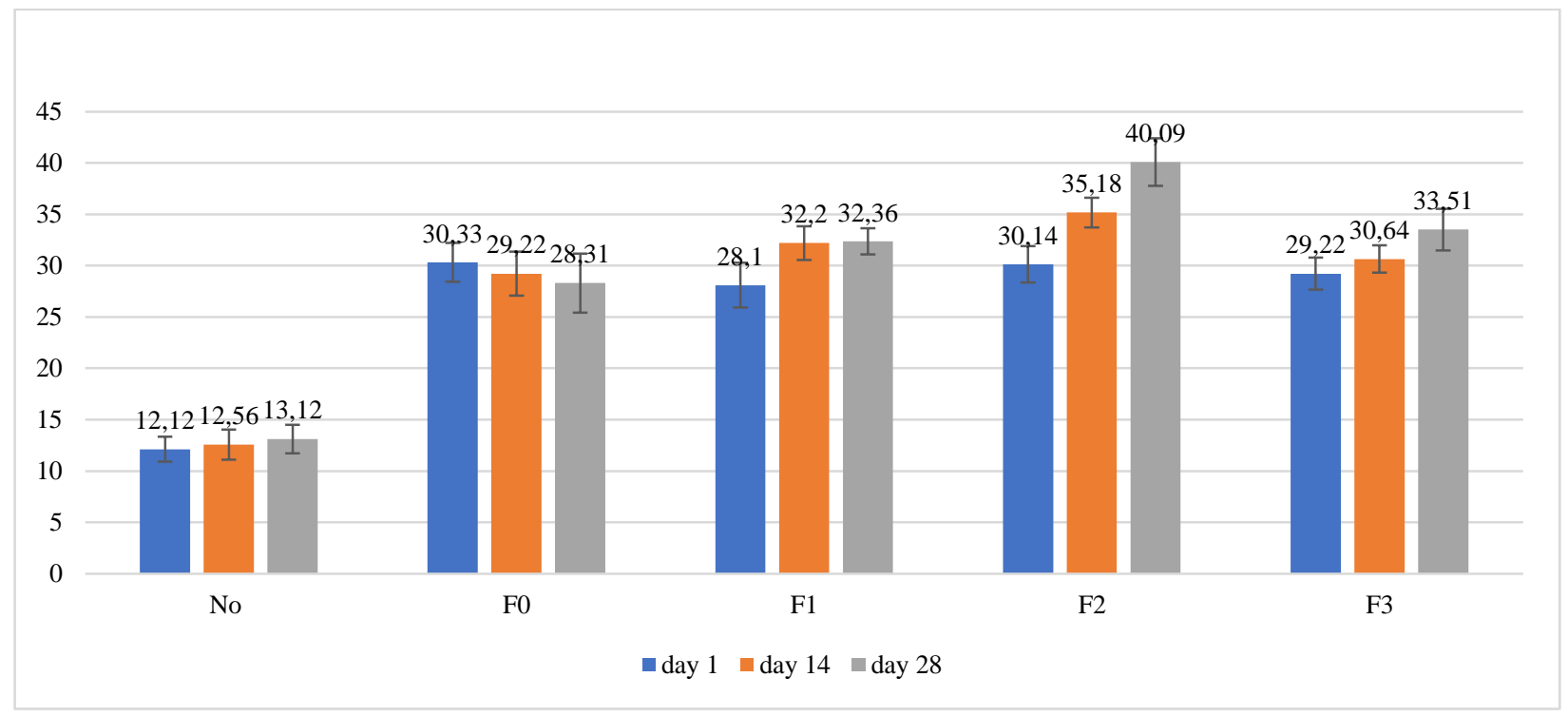

Figure 3 Analysis of superoxide dismutase (SOD)

*N0 normal group with no extract and high cholesterol diet, $\mathbf{F 0 = ~ h y p e r c h o l e s t e r o l e m i c ~ c o n t r o l ~ g r o u p ~ ( h i g h ~ c h o l e s t e r o l ~ d i e t ) , ~ T r e a t m e n t ~ g r o u p s ~ F 1 , ~ F 2 , ~ a n d ~ F 3 ~ ( h i g h ~}$ cholesterol diet +extract)

\section{Catalase (CAT)}

The statistical analysis demonstrated a significant $(p \leq 0.05)$ effect of the variables (treatments and time intervals) on the catalase enzyme level in experimental rats. The results for the levels of catalase are mentioned in table 4 . The catalase levels elevated from $21.81 \pm 1.51 \mathrm{IU} / \mathrm{L}\left(0\right.$ day) to $23.19 \pm 1.72\left(14^{\text {th }}\right.$ day) and $25.82 \pm 2.11$
( $28^{\text {th }}$ day), respectively. While, in comparison to $\mathrm{F}_{\mathrm{o}}(22.17 \pm 2.45 \mathrm{IU} / \mathrm{L})$, there was an elevation displayed in $F_{1}(24.28 \pm 1.82 \mathrm{IU} / \mathrm{L}), \mathrm{F}_{2}(24.88 \pm 2.30 \mathrm{IU} / \mathrm{L})$ and $\mathrm{F}_{3}$ $(23.76 \pm 1.41 \mathrm{IU} / \mathrm{L})$, respectively. The percentage increase showed by the experimental groups were $8.69 \%, 10.89 \%$ and $6.69 \%$; highest recorded for $\mathrm{F}_{2}$. 
Table 4 analysis of catalase (CAT)

\begin{tabular}{|c|c|c|c|c|c|}
\hline Parameter & Treatments & Interval of days & & & \\
\hline \multirow{7}{*}{ Catalase (IU/L) } & & 0 day & $15^{\text {th }}$ day & $28^{\text {th }}$ day & Means \\
\hline & No & $13.17 \pm 1.23$ & $13.05 \pm 1.45$ & $12.99 \pm 1.29$ & $13.07 \pm 1.32$ \\
\hline & F0 & $25.11 \pm 1.23$ & $21.51 \pm 2.33$ & $19.90 \pm 2.11$ & $22.17 \pm 2.45^{b}$ \\
\hline & $\mathrm{F} 1$ & $21.99 \pm 2.87$ & $24.05 \pm 1.43$ & $26.82 \pm 2.67$ & $24.28 \pm 1.82^{\mathrm{a}}$ \\
\hline & $\mathrm{F} 2$ & $20.35 \pm 2.87$ & $23.10 \pm 2.10$ & $31.19 \pm 2.65$ & $24.88 \pm 2.30^{\mathrm{a}}$ \\
\hline & F3 & $20.15 \pm 1.98$ & $24.12 \pm 1.20$ & $25.01 \pm 1.08$ & $23.76 \pm 1.41^{\mathrm{ab}}$ \\
\hline & Means & $21.9 \pm 1.51^{\mathrm{c}}$ & $23.19 \pm 1.72^{b}$ & $25.75 \pm 2.11^{\mathrm{a}}$ & \\
\hline
\end{tabular}

*N0 normal group with no extract and high cholesterol diet, F0= hypercholesterolemic control group (high cholesterol diet), Treatment groups F1, F2, and F3 (high cholesterol diet +extract)

\section{DISCUSSION}

Hypercholesterolemia or dyslipidemia referred as abnormal blood lipid/fat levels Hypercholesterolemia termed as high levels of cholesterol in the blood. Hypercholesterolemia is a risk factor for many diseases like heart diseases, diabetes, obesity, coronary heart diseases.so their levels must be normal in the body.a study reported that lignin secoisilaricriesinol diglucoside (SDG) in mice reduced the accumulation of fat in liver, and reduce the visceral fat accumulation in hyperlipidemia, hypercholesterolemia, hyperinsulimia and hypereptinaemia (Dyck, Heigenhauser and Bruce, 2006). Present study reported the same that defatted flaxseed extract lowers the cholesterol levels in hypercholesterolemic rats. A study was conducted on rabbits and 5 groups were made and $40 \mathrm{mg} / \mathrm{m}$ flaxseed lignin (defatted flaxseed) was given to them and blood samples were analyzed after treatment. the results showed significant decrease in lipid profile and inhibit lipid peroxidation. They reported the mean of cholesterol $143.8 \pm 13.9$ in rabbits. Similarly, Prasad in 2005 reported that flax lignin shows significan reduction in cholesterol levels with a dose of $40 \mathrm{mg} / \mathrm{kg}$ b.w when administered to 60 days (Dodin et al., 2006). A study was conducted by Zang and his fellows according to that a dose of $300 \mathrm{mg}$ SDG was given to the group and it showed significant difference in in TC and LDL levels. They reported the reduction in range of 22.0 to $24.38 \%$ in TC and LDL levels over a dose of $600 \mathrm{mg}$ for $6-8$ weeks. Many studies have been done on defatted flaxseed. It was noted previously that consumption of $40 \mathrm{~g}$ flaxseed/d with lowers amount of lignin (21 $\mathrm{mg}$ ) for 12 months did not showed more effect on cholesterol level in postmenopausal women. There are many evidences from literature that reports the lipid lowering effects of flaxseed, flax lignin and defatted flaxseed. All of these studies shows its potential against hypercholesterolemia (Dupasquier et al. 2005). In a study it was reported (a systematic review) in which 9 clinical trials were done 6 out 9 showed significant decrease in total cholesterol and LDL levels when administered with flaxseed supplementation (Bassett $\boldsymbol{e t}$ al., 2011). I has been stated in literature many times that lignin SDG from defatted flaxseed possess hypercholesterolemic and anti-atherogenic effects and SDG is the most likely component that have lipid lowering effects and reduce the plasma lipid profile. And reported by scientists in the findings that consumption of flaxseed daily in diet reduce the cholesterol (TC) levels by $6-11 \%$ and LDL by $9-18 \%$ normal patients while the levels of reduction in $\mathrm{TC}$ was $5-17 \%$ in hypercholesterolemic subjects and it was evident by their study that flaxseed lignin provide lipid lowering actions. This finding is close to our finding as in our study it reduced to $16 \%$. And the levels of cholesterol dropped more with defatted flaxseed as compared to whole flaxseed (Truan et al., 2012).

Hypolipidemic effects of flax lignin is due to multi mechanisms that have been reported in earlier studies, flax lignin is involved in increase of protein levels 7-a hydroxylase that converts cholesterol to bile. A study showed that SDG from flaxseed have an effective scavenging property of reactive oxygen species that inhibit lipid peroxidation through metal ions chelation (Mohammadi et al. 2006). It was reported in study and it is evident that supplementation with defatted flaxseed was observed to have lowered total cholesterol, LDL cholesterol concentrations, and Apo lipoprotein B in comparison to the control treatment. Our findings on defatted flaxseed extract had shown positive effect on elevated LDL levels and suggest that extract of defatted flaxseed lowers the levels of LDL in the body. In view of earlier studies on hyperlipidemic adults experimented with $50 \mathrm{~g} /$ day of partially defatted flaxseed meal reduces the cholesterol $4.6 \%$ and LDL by $7.6 \%$ in 3 weeks. Similarly, Hallund studied the direct effect of flax lignin extract on plasma lipid profile. whereas a study reported that $500 \mathrm{mg} /$ day of flaxseed extract of lignin, reduced the plasma lipids in healthy women over a period of 6 weeks diet (Hallund et al., 2006) Similarly zhang and his fellows in 2008 reported that SDG of dose $300 \mathrm{mg}$ and $600 \mathrm{mg} / \mathrm{day}$ in adults having high lipid profile reduce the LDL levels by $24 \%$ and tota cholesterol by $22 \%$.

Lignin content of flaxseed appears to be a contributing factor for hypolipidemic effect of flaxseed. Van Niekerk and his fellows reported in their studies that decrease in the serum TC and LDL levels is due to SEG content in Partial lignin present in Partially defatted flaxseed. Flaxseed lignin Known to reduce the hypercholesterolemic parameters that include TC, TG and LDL. Several mechanisms have been proposed regarding how flax lignin reduce the cholesterol levels. Increase in excretion of bile acids by flaxseeds ingestion augments the removal of bad cholesterol (LDL) and amend the liver metabolism in a way that enhance the LDL cholesterol removed by hepatocytes, and also increases the LDL receptors ( Zatta et al., 2002). The other striking finding shows that flax lignans almost standardized the lipid profiles parameters in liver of rabbit, and become almost normal levels of control groups. The widely held studies report that flaxseed modestly reduces TC $(6 \%-11 \%)$ and LDL cholesterol $(9 \%-18 \%)$ levels in normolipidemic and hypercholesterolemic patients i.e. TC (4.6\%-17\%), LDL cholesterol (3.9\%-10\%) (Sawant et al., 2015).

Conversely, results in a study reported that the increase in HDL levels of rabbits administered with treatment for 60 days, and these were consistent with previous literature that serum HDL levels tend to be increased when hypercholesterolemic rabbits treated for 120 days. However, some studies suggest that defatted flaxseed showed no effect on serum HDL levels. results of another study is showing these values of percentage reduction as Total $\mathrm{C}(\mathrm{mmol} / \mathrm{L}) 5.5 \pm 1.2$ HDL-C $(\mathrm{mmol} / \mathrm{L}) \quad 1.4 \pm 2.8$, LDL-C $(\mathrm{mmol} / \mathrm{L}) \quad 9.7 \pm 1.8$, Triacylglycero $(\mathrm{mmol} / \mathrm{L}) 10.2 \pm 4.8 .20$ D.E.C cintra et al.,2006 reported the reduction in lipid profile by flaxseed and presented means was total cholesterol $60.87 \pm 7.02$, HDL $41.57 \pm 6.96$, TG $49.54 \pm 6.57$, LDL $0.68 \pm 0.14$. Irregular lipid and lipoprotein metabolism plays an important part in hypertensive rats as well (Sawant et al. 2015). Lipid peroxidation, oxidative stress and changes in the lipid metabolism is the reason behind decreased levels of HDL and increase in level of other parameters like LDL, VLDL and TC (Mandasescu et al., 2005). it was reported in study and it is evident that Dietary supplementation with partially defatted flaxseed reduced serum concentrations of total cholesterol, LDL cholesterol, and Apo lipoprotein B compared with the control treatment.

Similarly, Amin et al who found that Rats fed high fat diet for 12 weeks showed a significant increase in the lipid profile LDL and TG, also it was also found that Plasma triglyceride was elevated by about $85-90 \%$ in high-fat fed rats $(30 \%)$ for 8 weeks. all these evidence showed that high levels of triglycerides linked to many diseases including hypercholesterolemia ( Stuglin and Parasad,2005).flaxseed meal reduce the cholesterol levels i.e. Total cholesterol, $\mathrm{mmol} / \mathrm{L} 3.53 \pm 0.05$ and Triglyceride, $\mathrm{mmol} / \mathrm{L} 4.09 \pm 0.34$. Similar addition of flaxseed extracts has also been linked with betterment of lipid serum profiles. Addition of $20 \%$ flaxseed in rat diet lowered total cholesterol level, triglyceride (TG) level, and low-density lipoprotein (LDL) cholesterol level by 21, 34, and 23\%, respectively( Matusiewicz et al.,2015) . results of another study is showing these values of percentage reduction as Total $\mathrm{C}(\mathrm{mmol} / \mathrm{L}) 5.5 \pm 1.2$, HDL-C $(\mathrm{mmol} / \mathrm{L}) 1.4 \pm 2.8, \mathrm{LDL}-\mathrm{C}(\mathrm{mmol} / \mathrm{L}) 9.7 \pm 1.8$, Triacylglycerol $(\mathrm{mmol} / \mathrm{L}) 10.2 \pm$ 4.8. It was reported the reduction in lipid profile by flaxseed and presented means was total cholesterol $60.87 \pm 7.02$, HDL $41.57 \pm 6.96$, TG 49.54 \pm 6.57 , LDL 0.68 \pm 0.14 (Girard et al., 2005). These reactive oxygen species have been shown damage to proteins, carbohydrates and DNA in in-vitro and in-vivo models as reported in literature (Rajeesha et al., 2006). Therefore it is important to analyze these levels for antioxidant status. Our study reported to have Safe levels of SOD and catalase insures that the defatted flaxseed extract has antioxidant property. The antioxidant also raise the levels of endogenous defense mechanism by the regulation of genes expression that encode for the enzymes superoxide dismutase (SOD), catalase, glutathione peroxidase, or lipid peroxidase. Our study has the mean values for catalase as $18 \%, 20.7 \%$ and $16 \%$ in treatment group F1, F2, F3 respectively. While for SOD it was calculated $12.7 \%, 25 \%$ and $12.77 \%$ in F1, F2, and F3 groups respectively. According to in-vitro and in-vivo studies, many antioxidants have been shown to have protective effect as hepatocytes and nephrocytes against lipid peroxidation and inflammation. So they prevent in the onset of hepatic neurosis and kidney damage in hypercholesterolemia subjects (Mohdaly et al., 2010).

Natural antioxidants are present in the form of Phenolics, coumarins, Xanthons, lignans, Tannins, lycopene and beta carotene (Jeong et al., 2004). Found in leaves, seeds, and oil of the plant material. It has been reported previously that antioxidants improve human health and inhibit cancer cells, improve cardiovascular diseases and metabolic disorders like diabetes (Zuk et al., 2011). Reported in a research that, a dose of $10.0 \%$ flaxseed showed the restoration of $95.02 \%, 182.31 \%$, and $136.0 \%$ of catalase, SOD, and peroxidase in a group administered with flaxseed. In another study it was reported to have antioxidant activity of flaxseed in albino rats feed with $5.0 \%$ and $10.0 \%$ of flaxseed $(0.75$ and $1.5 \mathrm{~g} \mathrm{~kg}-1$ ) for a period of 14 days followed by animal trilas with $2.0 \mathrm{~g} \mathrm{~kg}-1 \mathrm{~b} . \mathrm{w}$. $\mathrm{CCl} 4$ as toxin. catalase, superoxide dismutase (SOD), and peroxidase was measured CCL4 induced rats having dose of $2.0 \mathrm{~g} \mathrm{~kg}-1 \mathrm{~b} . \mathrm{w}$. reduced the effect of different antioxidant enzymes such as catalase, superoxide dismutase (SOD), and 
peroxidase by $34.6 \%, 47.86 \%$, and $52.0 \%$, respectively. The present study on defatted flaxseed showed more potential than other studies. Researches claimed the clear results regarding flaxseed constituents and its antioxidant activity. Flaxseed constituents as an antioxidant as seen by renewal of liver enzymes, which were different from normal to one due to harmfulness induced by toxin (CCl4). Hence it was essential to investigate the oxidant/antioxidant status of the rats. SOD levels in the study of flaxseed extract on winster rats was reported to have mean value of $9.585 \pm 0.361$ for extract (flaxseed concentrate) FLC $(500 \mathrm{mg} / \mathrm{kg})$ in myocardial damage in doxorubicin-induced rats along with high cholesterol levels (Zanwar et al., 2013).

\section{CONCLUSION}

Present findings demonstrate that defatted flaxseed extract lowers the elevated serum lipid profile in hypercholesterolemic subjects. The treatment provides significant reduction in TC, LDL and triglycerides (TG) levels in the experimental rats. Microwave assisted extraction is found to be beneficial technique for extraction as it is cheap, less time consuming and efficient Defatted flaxseed extract presents a source of valuable minerals, fiber, phenolic and antioxidants. In-vitro \& in-vivo studies on defatted flaxseed extract proved its efficacy and therapeutic potential against hypercholesterolemia. It is the richest source of dietary fiber and lignin, SDG is chief lignin found in defatted flaxseed. Flaxseed or defatted flaxseeds had great therapeutic potential reported in previous studies; against hypercholesterolemia and other diseases also i.e. diabetes, obesity, heart disease, cancer and hormonal issues. Therefore present study agrees with them. It possesses antioxidant activity and this effect may reduce the risk of other lifestyle related ailments like diabetes, atherosclerosis \& hypertension.

Acknowledgment: The authors would like to thank University Institute of Diet and Nutritional Sciences, Faculty of Allied health sciences The University of Lahore for their cooperation and all the fellows.

\section{REFRENCES}

Abedi, A. S., Rismanchi, M., Shahdoostkhany, M., Mohammadi, A., \& Mortazavian, A. M. (2017). Microwave-assisted extraction of Nigella sativa L. essential oil and evaluation of its antioxidant activity. Journal of Food Science and Technology, 54(12), 3779-3790. https://doi.org/10.1007/s13197-017-2718-1 Aslam, A., Khalil, A. A., Shahid, B., Aadil, R. M., Faiz-ul-Hassan, S., Khan, A A., \& Aqsa, R. (2019). Comparison of proximate composition and mineral profiling of defatted flaxseed cake obtained from three different varieties. Pakistan Journal of Food Sciences, 29(2), 15-18. https://psfst.org/paper files/3807 a3094d4b7351fe4b91b3418895124128.pdf Bassett, C. M., McCullough, R. S., Edel, A. L., Patenaude, A., LaVallee, R. K., $\&$ Pierce, G. N. (2011). The $\alpha$-linolenic acid content of flaxseed can prevent the atherogenic effects of dietary trans fat. American Journal of Physiology-Heart and Circulatory Physiology, 301(6), H2220-H2226. https://doi.org/10.1152/ajpheart.00958.2010

Dyck, D. J., Heigenhauser, G. J., \& Bruce, C. R. (2006). The role of adipokines as regulators of skeletal muscle fatty acid metabolism and insulin sensitivity. Acta physiologica, 186(1), 5-16. $\quad$ https://doi.org/10.1111/j.17481716.2005.01502.x

Stuglin, C., \& Prasad, K. (2005). Effect of flaxseed consumption on blood pressure, serum lipids, hemopoietic system and liver and kidney enzymes in healthy humans. Journal of Cardiovascular Pharmacology and Therapeutics, 10(1), 23-27. https://doi.org/10.1177\%2F107424840501000103

Dupasquier, C. M., Weber, A. M., Ander, B. P., Rampersad, P. P., Steigerwald, S., Wigle, J. T., ... \& Lukas, A. (2006). Effects of dietary flaxseed on vascular contractile function and atherosclerosis during prolonged hypercholesterolemia in rabbits. American Journal of Physiology-Heart and Circulatory Physiology, 291(6), H2987-H2996. https://doi.org/10.1152/ajpheart.01179.2005

El-Newary, S. A., Ibrahim, A. Y., Osman, S. M., \& Wink, M. (2018). Evaluation of possible mechanisms of Cordia dichotoma fruits for hyperlipidemia controlling in Wistar albino rats. Asian Pacific Journal of Tropical Biomedicine, 8(6), 302. http://www.apjtb.org/text.asp?2018/8/6/302/235325

Girard, A., Madani, S., El Boustani, E. S., Belleville, J., \& Prost, J. (2005) Changes in lipid metabolism and antioxidant defense status in spontaneously hypertensive rats and Wistar rats fed a diet enriched with fructose and saturated fatty acids. Nutrition, 21(2), 240-248. https://doi.org/10.1016/j.nut.2004.04.022

Hallund, J., Ravn-Haren, G., Bügel, S., Tholstrup, T., \& Tetens, I. (2006). A lignan complex isolated from flaxseed does not affect plasma lipid concentrations or antioxidant capacity in healthy postmenopausal women. The Journal of Nutrition, 136(1), 112-116. https://doi.org/10.1093/jn/136.1.112

Jeong, S. M., Kim, S. Y., Kim, D. R., Jo, S. C., Nam, K. C., Ahn, D. U., \& Lee, S. C. (2004). Effect of heat treatment on the antioxidant activity of extracts from citrus peels. Journal of Agricultural and Food Chemistry, 52(11), 3389-3393. https://doi.org/10.1021/jf049899k

Mohammadi, M., ALIPOUR, M., VATANKHAH, A., \& ALIPOUR, M. (2006) Effects of high cholesterol diet and parallel chronic exercise on erythrocyte primary antioxidant enzymes and plasma total antioxidant capacity in Dutch rabbits. https://www.sid.ir/en/journal/ViewPaper.aspx?id=50294

Mandaşescu, S., Mocanu, V., Dăscaliţa, A. M., Haliga, R., Nestian, I., Stitt, P. A. \& Luca, V. (2005). Flaxseed supplementation in hyperlipidemic patients. Revista medico-chirurgicala a societatii de Medici si naturalisti din Iasi, 109(3), 502506. https://pubmed.ncbi.nlm.nih.gov/16607740/

Mohdaly, A. A., Sarhan, M. A., Smetanska, I., \& Mahmoud, A. (2010). Antioxidant properties of various solvent extracts of potato peel, sugar beet pulp and sesame cake. Journal of the Science of Food and Agriculture, 90(2), 218 226. https://doi.org/10.1002/jsfa.3796

Mali, A. V., Padhye, S. B., Anant, S., Hegde, M. V., \& Kadam, S. S. (2019) Anticancer and antimetastatic potential of enterolactone: clinical, preclinical and mechanistic perspectives. European Journal of Pharmacology, 852, 107-124 https://doi.org/10.1016/j.ejphar.2019.02.022

Matusiewicz, M., Kosieradzka, I., Zuk, M., \& Szopa, J. (2015). Effect of dose and administration period of seed cake of genetically modified and non-modified flax on selected antioxidative activities in rats. International Journal of Molecular Sciences, 16(6), 14259-14275. https://doi.org/10.3390/ijms160614259 Naik, H. S., Srilatha, C., Sujatha, K., Sreedevi, B., \& Prasad, T. N. V. K. V. (2018). Supplementation of whole grain flaxseeds (Linum usitatissimum) along with high cholesterol diet and its effect on hyperlipidemia and initiated atherosclerosis in Wistar albino male rats. Veterinary world, 11(10), 1433 https://dx.doi.org/10.14202\%2Fvetworld.2018.1433-1439

Rajesha, J., Murthy, K. N. C., Kumar, M. K., Madhusudhan, B., \& Ravishankar, G. A. (2006). Antioxidant potentials of flaxseed by in vivo model. Journal of Agricultural and Food Chemistry, 54(11), 3794-3799. https://doi.org/10.1021/jf053048a

Rahaman, M. A., Vel, D., Janardhan, B., Pragathi, K. N., \& Deep, R. (2013). Evaluation of the antihyperlipidemic and anti-atherosclerotic activities of ethanolic extract of Cissus pallida in atherogenic diet fed rat. International Journal of Pharmaceutical Research Scholars, 2(2), 1-3.

Russo, R., \& Reggiani, R. (2015). Phenolics and antioxidant activity in flax varieties with different productive attitude. International Food Research Journal, 22(4), 1736. http://ifrj.upm.edu.my/22\%20(04)\%202015/(60).pdf

Rajesha, J., Murthy, K. N. C., Kumar, M. K., Madhusudhan, B., \& Ravishankar, G. A. (2006). Antioxidant potentials of flaxseed by in vivo model. Journal of Agricultural and Food Chemistry, 54(11), 3794-3799. https://doi.org/10.1021/jf053048a

Sultan, M. T., Butt, M. S., Karim, R., Ahmed, W., Kaka, U., Ahmad, S., ... \& Zia-Ul-Haq, M. (2015). Nigella sativa fixed and essential oil modulates glutathione redox enzymes in potassium bromate induced oxidative stress. BMC complementary and Alternative Medicine, 15(1), 330 https://doi.org/10.1186/s12906-015-0853-7

Sawant, S. H., \& Bodhankar, S. L. (2016). Flax lignan concentrate reverses alterations in blood pressure, left ventricular functions, lipid profile and antioxidant status in DOCA-salt induced renal hypertension in rats. Renal Failure, 38(3), 411-423. https://doi.org/10.3109/0886022X.2015.1136895

Stuglin, C., \& Prasad, K. (2005). Effect of flaxseed consumption on blood pressure, serum lipids, hemopoietic system and liver and kidney enzymes in healthy humans. Journal of Cardiovascular Pharmacology and Therapeutics, 10(1), 23-27. https://doi.org/10.1177\%2F107424840501000103

Truan, J. S., Chen, J. M., \& Thompson, L. U. (2012). Comparative effects of sesame seed lignan and flaxseed lignan in reducing the growth of human breast tumors (MCF-7) at high levels of circulating estrogen in athymic mice. Nutrition and Cancer, 64(1), 65-71. https://doi.org/10.1080/01635581.2012.630165

Teh, S. S., Niven, B. E., Bekhit, A. E. D. A., Carne, A., \& Birch, J. (2015) Optimization of polyphenol extraction and antioxidant activities of extracts from defatted flax seed cake (Linum usitatissimum L.) using microwave-assisted and pulsed electric field (PEF) technologies with response surface methodology. Food science and Biotechnology, 24(5), 1649-1659. https://doi.org/10.1007/s10068-015-0214-9

Waszkowiak, K., Gliszczyńska-Świgło, A., Barthet, V., \& Skręty, J. (2015). Effect of extraction method on the phenolic and cyanogenic glucoside profile of flaxseed extracts and their antioxidant capacity. Journal of the American Oil Chemists' Society, 92(11-12), 1609-1619. https://doi.org/10.1007/s11746-0152729-x

Zanwar, A. A., Hegde, M. V., \& Bodhankar, S. L. (2013). Protective role of concomitant administration of flax lignan concentrate and omega-3-fatty acid on myocardial damage in doxorubicin-induced cardiotoxicity. Food Science and Human Wellness, 2(1), 29-38. https://doi.org/10.1016/j.fshw.2013.01.002

Zatta, P., Zambenedetti, P., Stella, M. P., \& Licastro, F. (2002). Astrocytosis, microgliosis, metallothionein-I-II and amyloid expression in high cholesterol-fed rabbits. Journal of Alzheimer's Disease, 4(1), 1-9. https://doi.org/10.3233/JAD2002-4101

Żuk, M., Dymińska, L., Kulma, A., Boba, A., Prescha, A., Szopa, J., ... \& Hanuza, J. (2011). IR and Raman studies of oil and seedcake extracts from natural and genetically modified flax seeds. Spectrochimica Acta Part A: Molecular and Biomolecular Spectroscopy, 78(3), 1080-1089. https://doi.org/10.1016/j.saa.2010.12.054 
Zanwar, A. A., Hegde, M. V., \& Bodhankar, S. L. (2013). Protective role of concomitant administration of flax lignan concentrate and omega-3-fatty acid on myocardial damage in doxorubicin-induced cardiotoxicity. Food Science and Human Wellness, 2(1), 29-38. https://doi.org/10.1016/j.fshw.2013.01.002 